\title{
Influence of Morphology of Maxillary Central Incisor on Expression of Torque using 2D Surface Scanning and Confirmation with 3D Photographic Model: An in vitro Study
}

\author{
${ }^{1}$ Achint Devendra Chachada, ${ }^{2}$ Ranjit H Kamble
}

\begin{abstract}
The aim of present study was to evaluate the influence of convexity of upper central incisor on expression of torque. The variation in crown root angle of maxillary central incisor and the co-relation between crown root angle and convexity of crown of maxillary central incisor was also assessed. Thirty extracted maxillary central incisors and a central incisor bracket (American Orthodontics $-\mathrm{R}$ oth prescription 0.018 inch slot) were used for the study. The study was carried out in three parts. In first part, proximal radiographs of each sample were traced and crown to root angle was measured. In second part, labial surface each sample was scanned using cyclone scanning system (Renishaw) to obtain profile image of each sample which were analyzed using AutoCAD 2002 software. Convexity of labial surfaces at various heights, i.e. $X+1, X+2, X+3, X-1$, $X-2, X-3$ was measured. Third part consisted of preparation of 3D photographic model of one randomly selected sample using Stereo Scan 3D (Breuckmann) machine and 3D composite image of central incisor bracket using Esson optical profile projector. Torque values at $X+1, X+2, X+3, X-1, X-2$, $X-3$ were $2.27^{\circ}, 5.08^{\circ}, 8.96^{\circ},-5.01^{\circ},-8.35^{\circ}$ and $-12.33^{\circ}$ respectively and mean value of crown to root angle of all 30 studied samples was $180.27^{\circ}$. It was concluded that when bracket is displaced 1,2 or $3 \mathrm{~mm}$ incisally, there is increase in lingual root torque by an average value of $2.27^{\circ}, 5.08^{\circ}$ or $8.96^{\circ}$ respectively while when bracket is displaced 1,2 or $3 \mathrm{~mm}$ gingivally, there is decrease in lingual root torque or increase in labial root torque by an average value of $5.01^{\circ}, 8.35^{\circ}$ or $12.33^{\circ}$ respectively. These findings were confirmed on analysis of $3 \mathrm{D}$ photographic model of one randomly selected sample.
\end{abstract}

Keywords: Maxillary central incisor, Torque bracket position, 3D tooth.

How to cite this article: Chachada AD, Kamble RH. Influence of Morphology of Maxillary Central Incisor on Expression of Torque using 2D Surface Scanning and Confirmation with 3D Photographic Model: An in vitro Study. World J Dent 2014;5(1):21-27.

\section{Source of support: $\mathrm{Nil}$}

Conflict of interest: None

\section{${ }^{1}$ Reader, ${ }^{2}$ Professor}

${ }^{1}$ Department of Orthodontics, Swargiya Dadasaheb Kalmegh S mruti Dental College, Nagpur, Maharashtra, India

${ }^{2}$ Department of Orthodontics, Sharad Pawar Dental College Wardha, Maharashtra, India

Corresponding Author: Achint Devendra Chachada Reader, Department of Orthodontics, Swargiya Dadasaheb Kalmegh Smruti Dental College, Nagpur, Maharashtra, India Phone: 07122710395, e-mail: achint.chachada@ gmail.com

\section{INTRODUCTION}

It has been noted that individual variations in dental anatomy, particularly in convexity of labial surface can produce considerable differences in torque expression. ${ }^{1}$ The final tooth position lies within the bracket and is not only dependent on archwire bending because of the bracket design. ${ }^{2,3}$ In addition, increased crown to root angle may limit the degree to which the roots can be torqued palatally due to an increased proximity of the roots to the palatal cortical plate of the alveolar process. ${ }^{4}$

Thus, in order to obtain good treatment results, brackets have to be accurately placed on a specific location on labial or buccal surface of each tooth, attempting to express the desired amount of torque and tip. This is influenced by tooth morphology, i.e. convexity of crown and crown root angle. The present study aims toward evaluation of influence of tooth morphology of upper central incisor on expression of torque with preadjusted bracket.

\section{MATERIALS AND METHODS}

The study was carried out in the Department of Orthodontics and D entofacial Orthopedics, Sharad Pawar Dental College, DM IMS Wardha, Maharashtra, India in association with Creative Tools, N oida, CA DScan Consultants and M ilestone Technologies, M umbai, India. Thirty extracted maxillary central incisors with absence of attrition, abrasion, caries and root resorption were taken as samples.

This study was carried out in three parts:

\section{Radiographic}

Proximal radiograph of each sample was taken using intraoral radiographic unit ( $X-M$ ind $^{T M} X$-ray system. Sr No. X M-0383 Satelec India) under following standardized condition - $15 \mathrm{~cm}$ - object to source distance, $0 \mathrm{~mm}$ - object film distance, $187 \mathrm{kVp}$ and 0.5 seconds exposure time. Each radiograph was then traced on lead acetate sheet using $4 \mathrm{H}$ pencil and following points were marked on tracings; Point I - midpoint of incisal edge, Point 0-midpoint on curvature of cementoenamel junction, Point A - most apical point on the root apex. Long-axis of root was determined by joining Point $\mathrm{A}$ and $\mathrm{O}$, Long-axis of crown was determined 


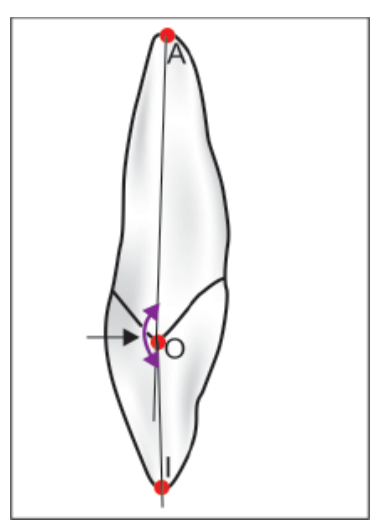

Fig. 1: Crown to root angle

by joining Point I and 0 . Crown to root angle of each sample was determined by measuring the angle between long axis of crown and longitudinal axis of root (Fig. 1).

\section{D Surface Scanning}

Labial surface of each sample was scanned using cyclone scanning system (R enishaw) to obtain profile image of each sample. Each sample was held on a custom made fixture which was then placed on the platform of machine. The probe of the machine was run from apex to the incisal edge of tooth and points were recorded at every $1 \mathrm{~mm}$ interval with accuracy level of $0.05 \mathrm{~mm}$. A ll the points were then joined to obtain a curve using IDEA S Software (Version 11) to obtain a curvature representing labial surface of tooth. Obtained images were then transferred to A utoCAD 2002 software and following points were marked on each tooth image (Figs 2 to 5); Point I- midpoint of incisal edge, Point Cmost apical point on curvature of cementoenamel junction, Point $X^{\prime}$ - midpoint on line joining $I$ and $C$, Point $X-$ orthogonal projection of $X^{\prime}$ on contour of labial convexity, representing midpoint of anatomic crown.

Three points, $X+1, x+2, x+3$, marked gingival to $X$ at $1 \mathrm{~mm}$ interval and three points $X-1, X-2, X-3$, marked incisal to $X$ at $1 \mathrm{~mm}$ interval. Perpendiculars to the tangent at each of these seven points, i.e. $X, X+1, X+2$, $X+3, X-1, X-2, X-3$ were drawn.

Following angles were then measured; angle between perpendiculars at $X$ and $X+1, X$ and $X+2, X$ and $X+3$, $X$ and $X-1, X$ and $X-2$, and $X$ and $X-3$ (Fig. 6).

$N$ egative (-) sign was assigned to the angles which were formed in counterclockwise direction from perpendicular at point $X$ while Positive $(+)$ sign was assigned to the angles which were formed in clockwise direction from perpendicular at point $X$.

\section{Preparation of 3D Photographic Model}

A three dimensional photographic model was prepared of a randomly selected sample using Stereo Scan 3D

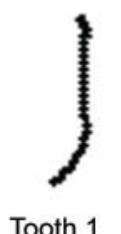

Tooth 1

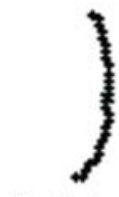

Tooth 3
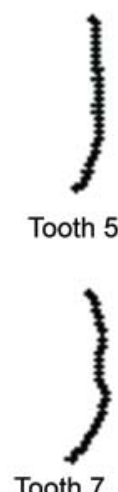

Tooth 7

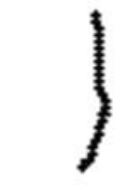

Tooth 9
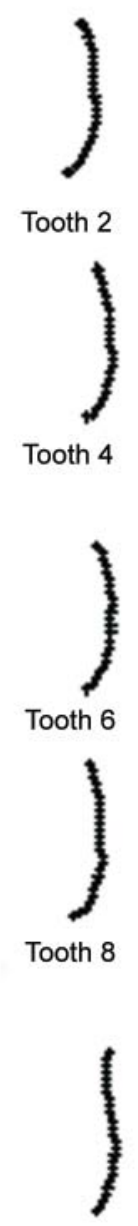

Tooth 10
Fig. 2: Profile image of sample no. 1 to 10 obtained from cyclone scanning system

(Breuckmann) machine with accuracy level of $0.05 \mathrm{~mm}$. (Fig. 7) A 3D composite image of central incisor bracket (A merican Orthodontics - Roth prescription 0.018 inch slot dimension) was prepared using Esson optical profile projector with accuracy level of $0.25 \mathrm{~mm}$ (Fig. 8). Image of bracket was positioned on 3D image of tooth at center of anatomical crown (FACC point). Then angle between long axis of slot of bracket and perpendicular to tangent at FA CC point was measured. This gives ideal torque value built into the bracket system. (A Il dimensions measured were in accuracy level of $0.000 \mathrm{~mm} /$ degrees) (Fig. 9).

The position of the bracket was changed occlusogingivally by $1 \mathrm{~mm}$ interval ( 3 positions apical to FACC point and three positions incisal to FACC point) and angle between slot of the bracket and perpendicular to tangent at FACC point was measured at each of these varied bracket positions.

\section{RESULTS}

The data obtained was subjected to statistical analyses. Results showed that there is considerable amount of angular 


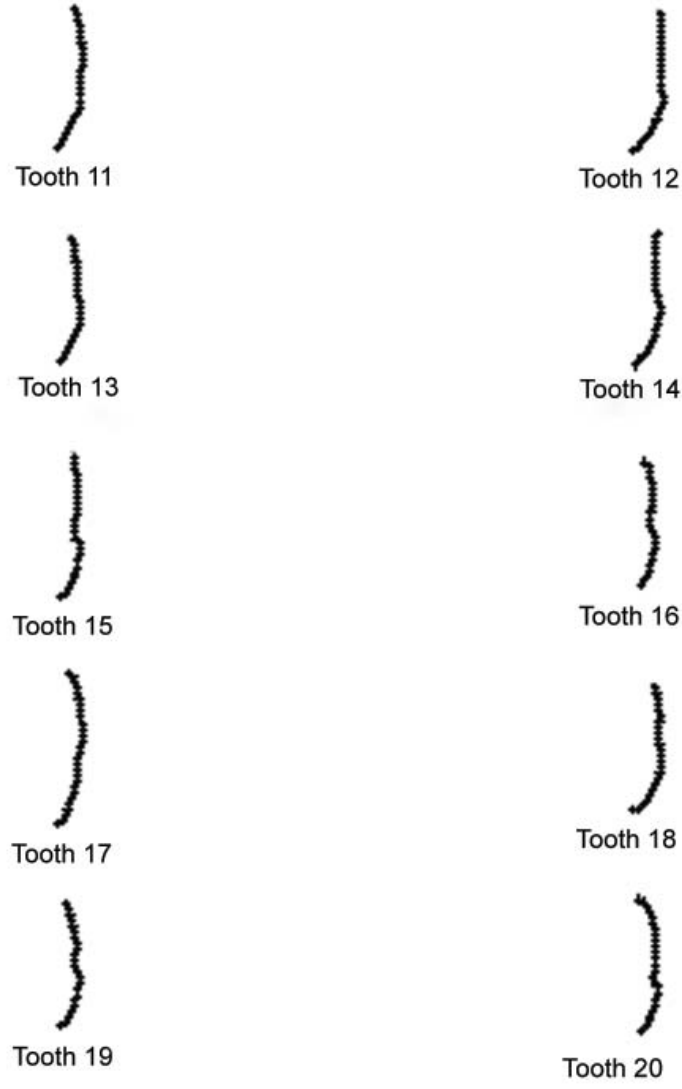

Fig. 3: Profile image of sample no. 11 to 20 obtained from cyclone scanning system

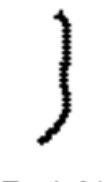

Tooth 21

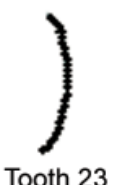

Tooth 23

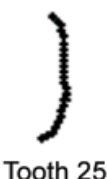

Tooth 25
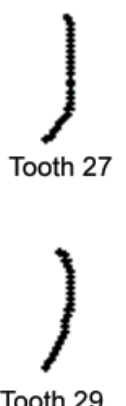

Fig. 4: Profile image of sample no. 21 to 30 obtained from cyclone scanning system

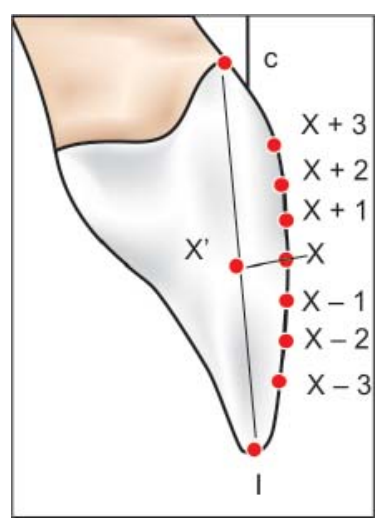

Fig. 5: Schematic representation showing the points $X^{\prime}, X, X+1$, $X+2, X+3, X-1, X-2, X-3$

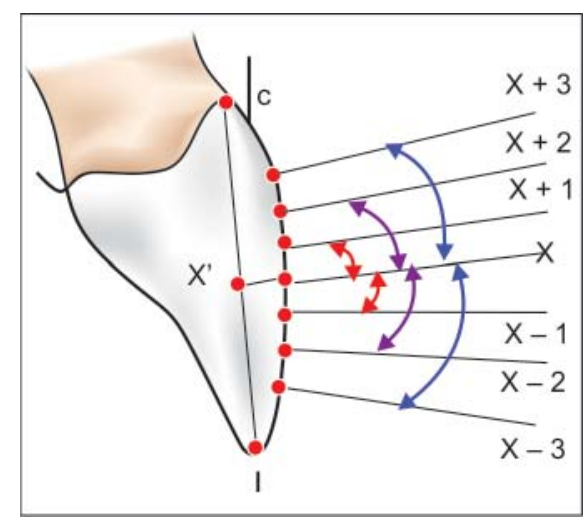

Fig. 6: Schematic representation showing the angles at $X+1$, $X+2, X+3, X-1, X-2, X-3$
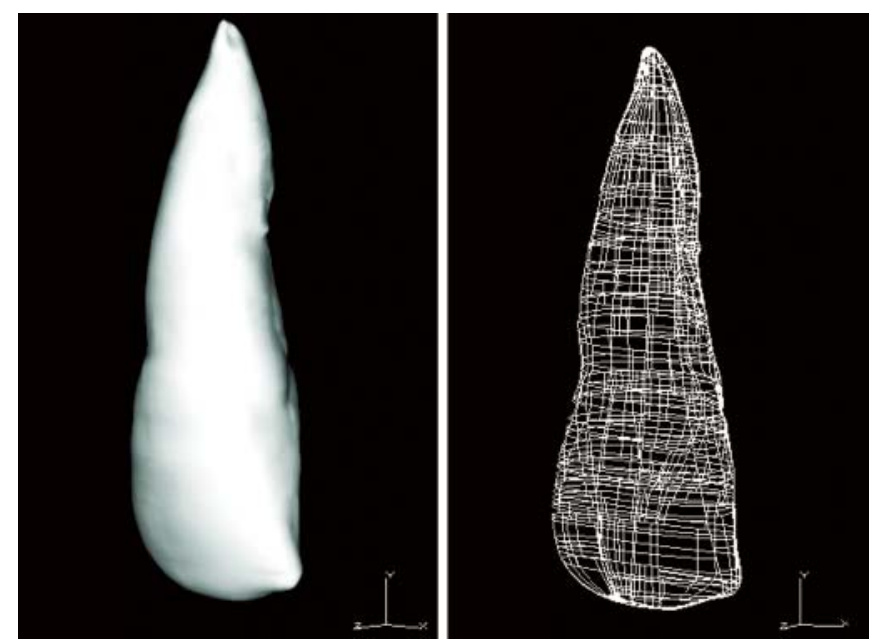

Fig. 7: Three dimensional photographic model of a randomly selected sample

variation among the points studied in relation to midpoint $(X)$. M ean values at $X-1, X-2, X-3, X+1, X+2$ and $X+3$ were $2.27^{\circ}, 5.08^{\circ}, 8.96^{\circ},-5.01^{\circ},-8.35^{\circ}$ and $-12.33^{\circ}$ respectively, while variance at these all points were $16.08^{\circ}$, $29.33^{\circ}, 47.36^{\circ}, 7.62^{\circ}, 14.58^{\circ}$ and $21.24^{\circ}$ respectively. M ean value of crown to root anglewas $180.27^{\circ}$ while the variance was 19.840 (Table 1 and Graph 1). 
Table 1: Descriptive statistics of studied angles $\left({ }^{\circ}\right)$

\begin{tabular}{llllllll}
\hline Angles & CRA & $X+1$ & $X+2$ & $X+3$ & $X-1$ & $X-2$ & $X-3$ \\
\hline Mean & 180.27 & -5.01 & -8.35 & -12.33 & 2.27 & 5.08 & 8.96 \\
SD & 4.45 & 4.01 & 5.42 & 6.88 & 2.76 & 3.82 & 4.61 \\
Variance & 19.84 & 16.08 & 29.33 & 47.36 & 7.62 & 14.58 & 21.24 \\
Standard error of & 0.15 & 0.13 & 0.18 & 0.23 & 0.09 & 0.13 & 0.15 \\
mean & & & & & & & \\
Median & 180.00 & -4.40 & -8.35 & -13.10 & 2.55 & 5.30 & 9.35 \\
Minimum & 173.00 & -17.60 & -20.80 & -30.60 & -3.60 & -4.60 & -1.70 \\
Maximum & 188.50 & 1.30 & 2.60 & 4.70 & 8.40 & 10.80 & 17.60 \\
\hline
\end{tabular}

Table 2: Pearson's correlation coefficient between crown root angle and sum of studied angle (absolute angle)

\begin{tabular}{llll}
\hline Statistics & Correlation & p-value & Significance \\
\hline $\begin{array}{l}\text { CRA vs sum of studied angle } \\
\text { (absolute angle) }\end{array}$ & -0.15 & 0.40 & $\begin{array}{l}\text { Nonsignificant } \\
p>0.01\end{array}$ \\
\hline
\end{tabular}

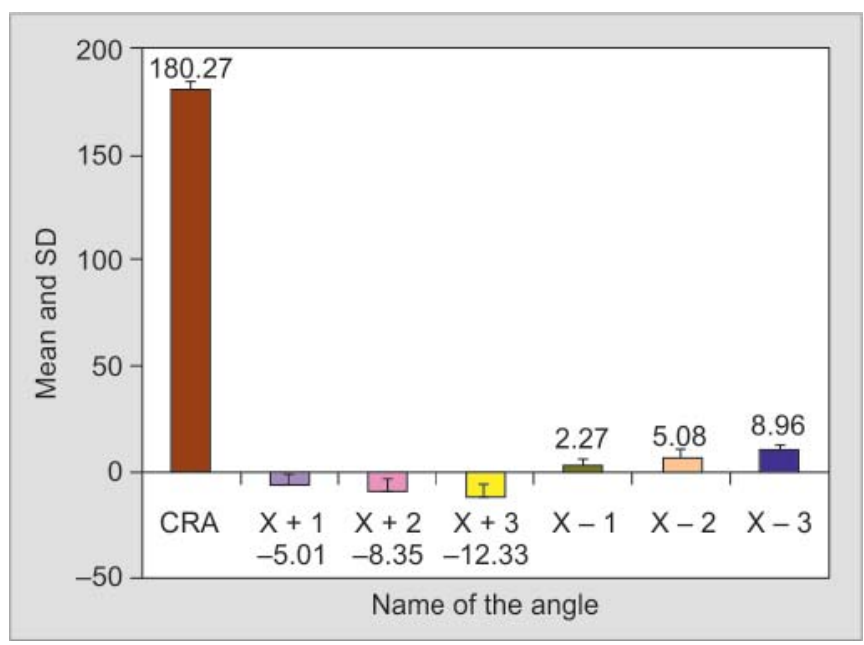

Graph 1: Mean and SD of studied angles $\left(^{\circ}\right)$

Pearson's co-relation test was applied to study the corelation between crown to root angle and labial surface convexity. Labial surface convexity was determined by summing up the absolute values of all the studied angles. Result showed that there was negative co-relation between the two, which was nonsignificant (Table 2 and G raph 2).

Results of the 3D study showed that the angulation of bracket slot at point $X$ was $11.825^{\circ}$. This indicates that the torque expression at point $X$ would be $11.825^{\circ}$, which is the approximate value of torque for maxillary central incisor in roth prescription $\left(12^{\circ}\right)$. W hen bracket was displaced incisally by $1 \mathrm{~mm}$ interval upto $3 \mathrm{~mm}$, values for torque were found to be $14.205^{\circ}, 18.205^{\circ}$, and $22.205^{\circ}$ respectively (Figs 10 to 12 ). This indicates that there was progressive increase in lingual root torque as bracket was displaced incisally. W hen bracket was displaced gingivally by $1 \mathrm{~mm}$ interval up to 3 $\mathrm{mm}$, values for torque were found to be $9.326^{\circ}, 7.035^{\circ}$ and $3.277^{\circ}$ respectively (Figs 13 to 15 ). This indicates that there was progressive decrease in lingual root torque as bracket was displaced gingivally.

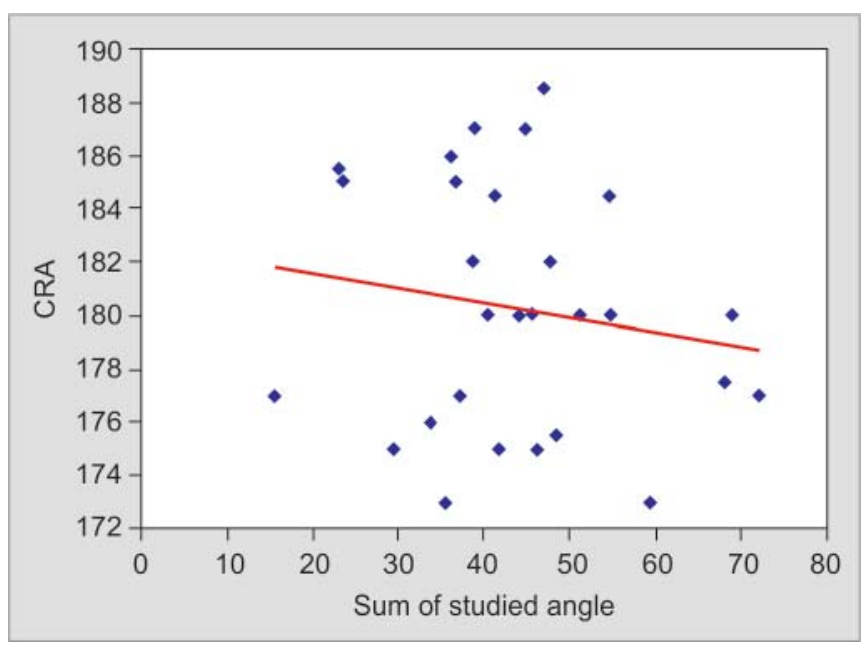

Graph 2: Pearson's correlation coefficient between crown root angle and sum of studied angles (absolute angle)

\section{DISCUSSION}

In the present study mean value of crow $n$ to root angle was found to be $180.27^{\circ}+4.45^{\circ}$. The angle showed considerable amount of variation from $173^{\circ}$ to $188.5^{\circ}$. Studies conducted by Bryant $\mathrm{RM}^{4-7}$ also showed wide variation in the crown to root angle. During orthodontic treatment, the crown to root angle is of major importance for final tooth position. Taking into consideration that a root, moved against the cortical plate, is at higher risk for root resorption, care should be taken to torque a tooth with a large CRA. Particularly in cases of class II div 2 malocclusion, CRA increases so that root is placed more lingual as compared to crown.

On the other hand, mean values at $X-1, X-2, X-3$, $X+1, X+2$ and $X+3$ were $2.27^{\circ}, 5.08^{\circ}, 8.96^{\circ},-5.01^{\circ}$, $-8.35^{\circ}$, and $-12.33^{\circ}$ respectively, while variance at these all points were $16.08^{\circ}, 29.33^{\circ}, 47.36^{\circ}, 7.62^{\circ}, 14.58^{\circ}$ and $21.24^{\circ}$ respectively. This shows that, when bracket is displaced 1,2 or $3 \mathrm{~mm}$ incisally, there is increase in lingual root torque by an average value of $2.27^{\circ}, 5.08^{\circ}$ or 

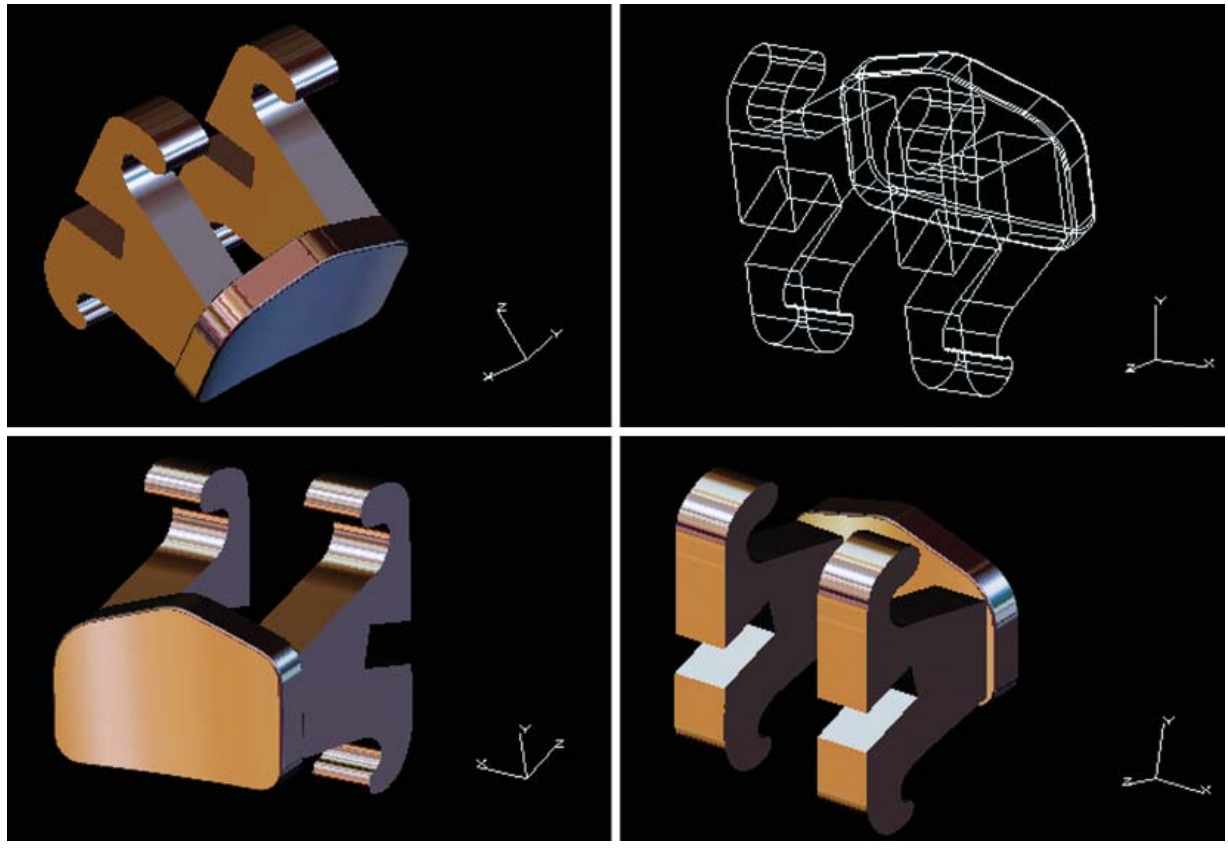

Fig. 8: Three-dimensional composite image of central incisor bracket (American orthodontics-Roth prescription 0.018 inch slot dimension)

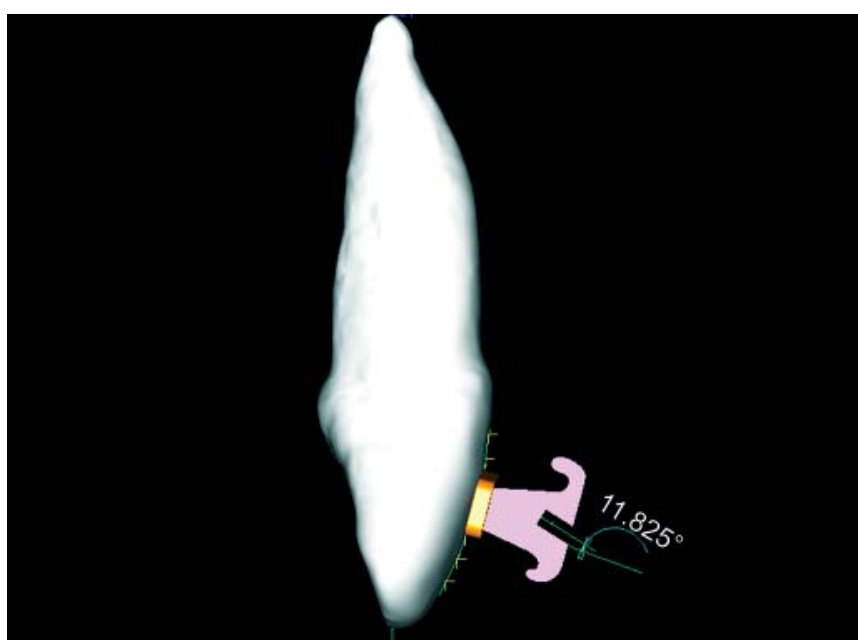

Fig. 9: Angle between long-axis of slot of bracket and perpendicular to tangent at FACC point

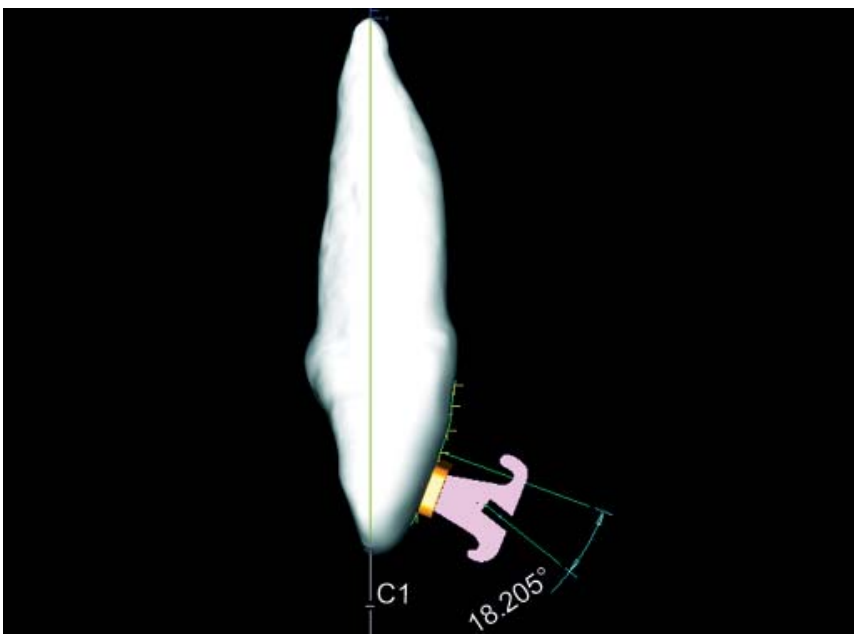

Fig. 11: Angle between long-axis of slot of bracket and perpendicular to tangent at FACC point at a point $2 \mathrm{~mm}$ incisal to FACC

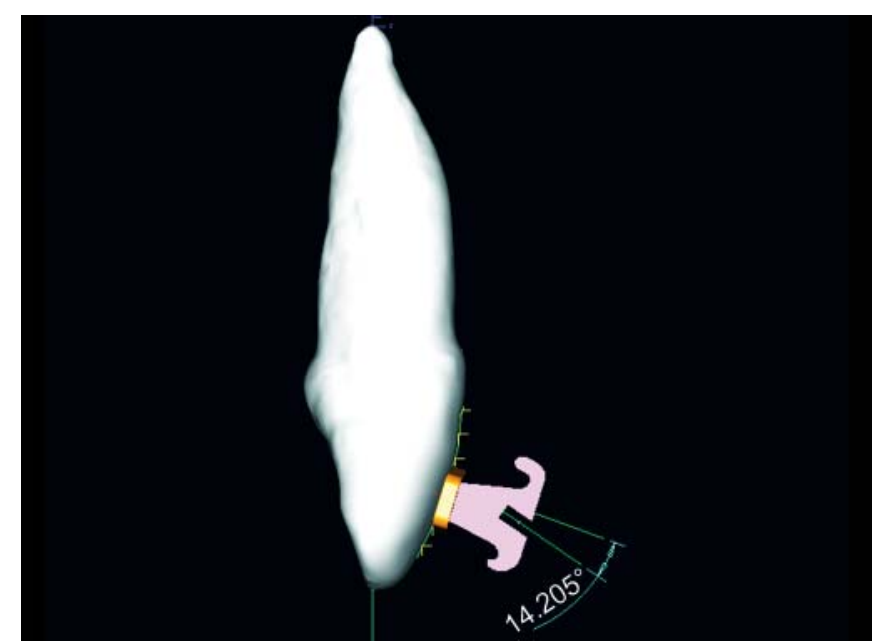

Fig. 10: Angle between long-axis of slot of bracket and perpendicular to tangent at a point $1 \mathrm{~mm}$ incisal to FACC

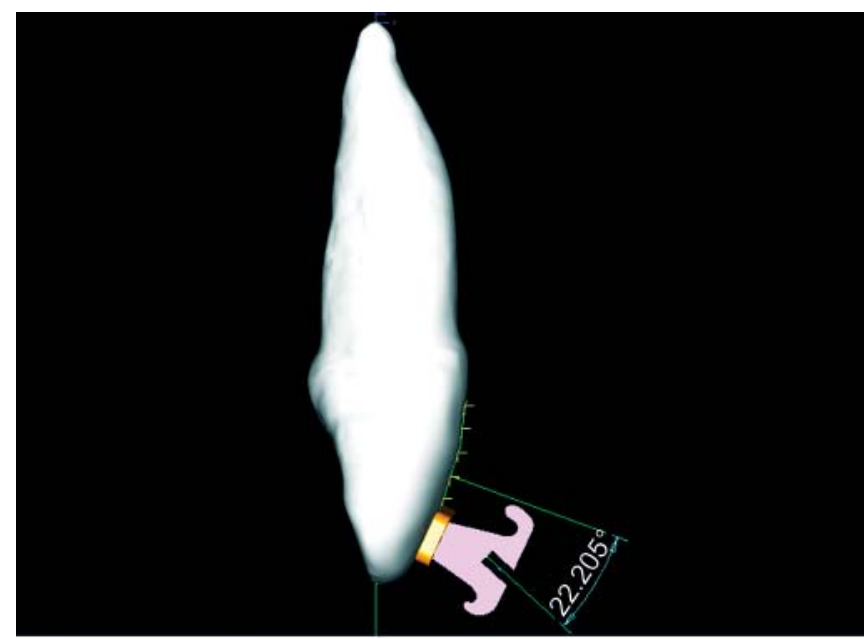

Fig. 12: Angle between long-axis of slot of bracket and perpendicular to tangent at FACC point at a point $3 \mathrm{~mm}$ incisal to $\mathrm{FACC}$ 


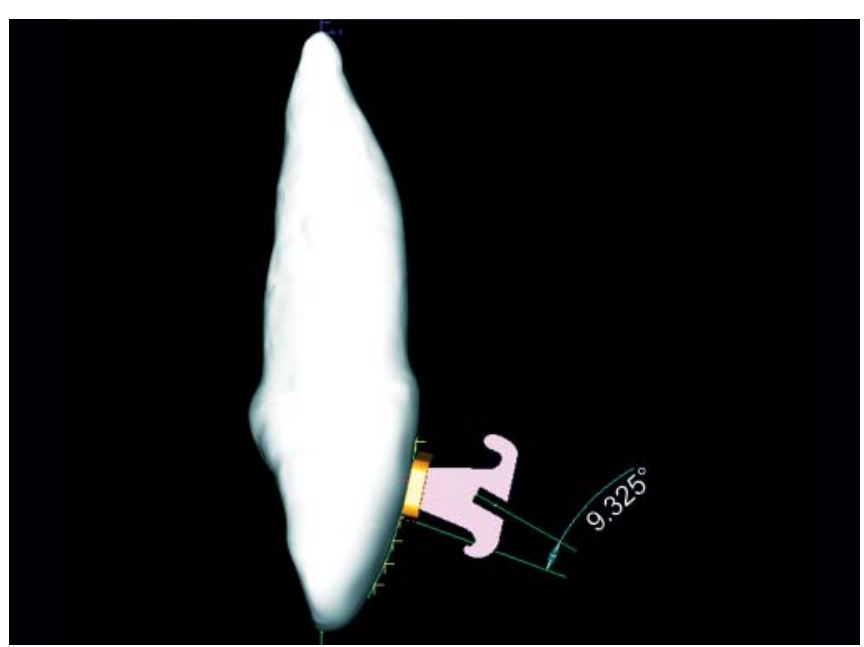

Fig. 13: Angle between long-axis of slot of bracket and perpendicular to tangent at FACC point at a point $1 \mathrm{~mm}$ gingival to FACC

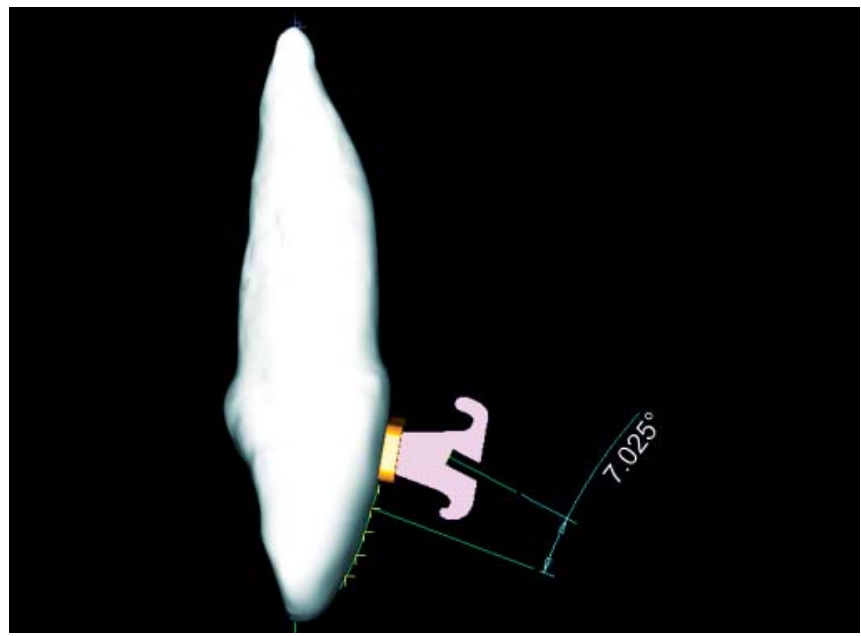

Fig. 14: Angle between long-axis of slot of bracket and perpendicular to tangent at FACC point at a point $2 \mathrm{~mm}$ gingival to FACC

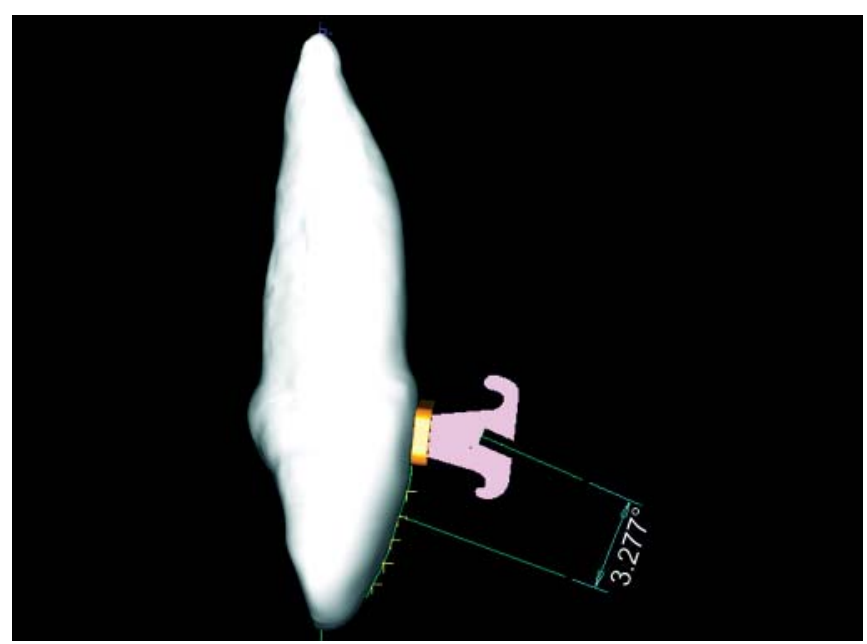

Fig. 15: Angle between long-axis of slot of bracket and perpendicular to tangent at FACC point at a point $3 \mathrm{~mm}$ gingival to $\mathrm{FACC}$

$8.96^{\circ}$ respectively. When bracket is displaced 1,2 or $3 \mathrm{~mm}$ gingivally, there is decrease in lingual root torque or increase in labial root torque by an average value of $5.01^{\circ}$, $8.35^{\circ}$ or $12.33^{\circ}$ respectively.
Bryant RM et al studied the variability in three morphologic features of the permanent maxillary central incisors. ${ }^{4}$ They found that mean value of labial surface angle for all samples was $15.1^{\circ} \pm 3.02^{\circ}$ with a range of $7^{\circ}-24^{\circ}$. This indicated that there is a wide range of convexity at mid-point of crown resulting in variation in expression of torque depending on the convexity at that point. However, they studied the variation in the convexity only at the midpoint of the crown. A s stated by Balut et al (1992); 8 Taylor and Cook $(1992)^{2}$ the clinician is able to bond brackets with an accuracy of $0.5 \mathrm{~mm}$ but the position of an upper incisor bracket may vary between 3.5 and $5.5 \mathrm{~mm}$ from the incisal edge. This variation in bracket position from ideal position will result in a different effect on the final torque of a tooth, because of a different vertical position. Thus the present study was undertaken to evaluate the variation in torque values at varying occlusogingival position of the bracket and not the variation at midpoint of crown.

Germane $\mathrm{N}$ et al studied the facial surface contours of 600 maxillary and mandibular teeth, including 50 of each type of tooth from central incisors to first molars. ${ }^{9}$ They concluded that facial surface contours do vary but not in a regular manner from incisal/occlusal to gingival areas. Vertical placement errors of $1 \mathrm{~mm}$ can alter torque values present by up to $10^{\circ}$ for the points studied. While the result of present study shows that vertical placement error does not alter the torque values uniformly.

One shortcoming in 2D scan was that the exact slot to tooth relationship was not represented. To overcome this, a $3 \mathrm{D}$ photographic model of one randomly selected sample and a 3D composite image of central incisor bracket was studied. Results showed that the angulation of bracket slot at point $X$ was $11.825^{\circ}$. This indicates that the torque expression at point $X$ would be $11.825^{\circ}$. When bracket was displaced gingivally by $1 \mathrm{~mm}$ interval up to $3 \mathrm{~mm}$, values for torque were found to be $9.326^{\circ}, 7.035^{\circ}$ and $3.277^{\circ}$ respectively. This indicates that there was progressive decrease in lingual root torque as bracket was displaced gingivally. When bracket was displaced incisally by $1 \mathrm{~mm}$ interval up to $3 \mathrm{~mm}$, values for torque were found to be 14.2050, 18.2050, and 22.2050 respectively. This indicates that there was progressive increase in lingual root torque as bracket was displaced incisal ly. These resul ts confirm the findings of the 2D scan carried out in this study. However, the results may vary in the clinical situation as tooth movement is a biologic process and thus the tissue resistance variable cannot be eliminated while predicting the amount and type of tooth movement. Hence, to increase the validity of this study in vivo studies can be carried out. 


\section{REFERENCES}

1. Gottlieb EL. The editor's corner-Torque talk. J Clin Orthod 1999;33:481-482.

2. Taylor NG, Cook PA. The reliability of positioning pre-adjusted brackets: an in vitro study. B I Orthod 1992;19:25-34.

3. Creekmore TD, Kunik RL. Straight wire: the next generation. A m J Orthod Dentofacial Orthop 1993;104:8-20.

4. B ryant RM, Sadowsky PL, Dent M, Hazelrig J B. Variability in three morphologic features of the permanent maxillary central incisor. A m J Orthod 1984;86:25-32.

5. Carlsson R, Ronnerman A. Crown-root angles of upper central incisors. A m J Orthod 1973;64:147-154.
6. Van Loenen M, Degrieck J, De Pauw G, Dermaut L. A nterior tooth morphology and its effect on torque. Eur J Orthod 2005; 27:258-262.

7. Hazarey PV, Shrivastav S. A comparison of morphological variations in permanent maxillary central incisors in class II div 2 with class II div 1 and class I malocclusion. J Ind Orthod Soc 1999;32:42-49.

8. B alut N , K lapper L, Sandrik J, B ow man D. Variations in bracket placement in the preadjusted orthodontic appliance. A m J Orthod Dentofacial Orthop 1992;102:62-67.

9. Germane N, B entley Jr, Isaacson RJ. Three biologic variables modifying faciolingual tooth angulation by Straight Wire A ppliances. A m J Orthod 1989;96:312-319. 